Received Date : $15-$ Feb-2016

Revised Date : 05-Jun-2016

Accepted Date : 27-Jun-2016

Article type : Special Issue

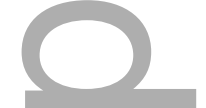

Corresponding author mail id:- n.chiavaroli@unimelb.edu.au

\title{
Knowing how we know: an epistemological rationale for the medical humanities
}

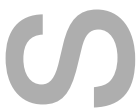

As we know, there are known knowns; there are things we know we know. We also know there are known unknowns; that is to say we know there are some things we do not know. But there are also unknown unknowns - the ones we don't know we don't know. (Donald Rumsfeld, former US Secretary of Defence)

\section{Abstract \\ Background}

Although it is increasingly being included in medical curricula internationally, the field of medical humanities still faces challenges to its role and place in the curriculum. Justifications supporting the inclusion of humanities content, methods, and perspectives in medical curricula have generally been proposed along instrumental, intrinsic and critical lines. However, recent literature in the field has turned to 'ways of knowing' as an alternative, essentially epistemological perspective on the matter. This involves the claim that the medical humanities align with and promote characteristic ways of understanding and practicing medicine, which are not adequately represented by traditional disciplinary frameworks.

\section{Discussion}

This is the author manuscript accepted for publication and has undergone full peer review but has not been through the copyediting, typesetting, pagination and proofreading process, which may lead to differences between this version and the Version of Record. Please cite this article as doi: $10.1111 /$ medu.13147

This article is protected by copyright. All rights reserved 
Such epistemological arguments aim to move beyond generic claims of medicine being both an 'art and science' to explore the way in which the humanities support the ultimate objectives of a medical education, in particular in relation to claims about requisite knowledge and typical reasoning. Not only can this help focus attempts at identifying and documenting relevant learning or clinical outcomes, it can potentially uncover evidence from educational outcomes research which may not have been the focus of previous inquiry in the medical humanities and which may in fact be associated, at least in part, with curricular activities formally associated with humanities disciplines.

\section{Conclusions}

An epistemological view of the humanities in medical education offers a significantly new way of conceptualising and communicating the potential role of the humanities in medical education. If clinical practice can be characterised as rational but interpretive, partly predictable yet fundamentally uncertain, and logical but also intuitive, it follows that educational training needs to facilitate such ways of knowing and thinking. An epistemological perspective enables the argument that the medical humanities are valuable not because they are more 'humane', but because they help constitute what it means to think like a doctor.

\section{Background}

When Donald Rumsfeld famously uttered during a press conference on the Iraq War the above words, some saw it as an insightful and universal articulation of the problem of truth and meaning. Others thought they had witnessed a shameless moment of political obfuscation. ${ }^{1}$ Whatever the case, the quote provides a useful window on the focus and concerns of epistemology - namely, the study of the nature, methods and validity of knowledge. In particular, it draws attention to the fact that knowledge is rarely simply a matter of knowing what is true or what is false. Epistemology teaches us that a discipline's underlying theory of knowledge has significant ramifications for how further knowledge is generated, how the discipline goes about determining what counts as knowledge, and what kinds of methods, it considers valid. These are crucial considerations for any field of intellectual endeavour, including the medical humanities. 
The field of medical humanities, or, increasingly, the 'health humanities' ${ }^{2}$, definable as 'an inter- and multidisciplinary field that explores contexts, experiences and critical and conceptual issues in medicine and health care $^{3}$ now has a relatively long history of academic literature. From its roots in the art therapy movement in the UK in the 1940s and medical school curricular reforms in the USA in the 1960s, ${ }^{4}$ the field has evolved and expanded to the stage where that literature can be surveyed and stock taken of the changes, developments, debates and revisions which it has undergone, as any field of academic inquiry must. Admittedly, proponents tend to be vague about which specific disciplines might legitimately be considered part of the field; but this is appropriate, as the emphasis on the interdisciplinary nature of the medical humanities means the individual disciplines are seen as less important than the perspective brought to bear on medical or health practice. As one scholar has expressed it, the medical humanities is concerned with 'the human experiences of medicine, seen through the humanities, reflected philosophically'. ${ }^{5}$ In practice, this means that any discipline or area of scholarship which lends itself to a humanistic, interpretive or qualitative perspective on such practice, can be said to 'belong' to the field. Accordingly, 'primary' disciplines such as art, literature, history, cultural studies and philosophy sit comfortably alongside applied fields such as ethics, communication skills or public health in this field, along with behavioural and social sciences such as anthropology, politics, psychology, and sociology. What ultimately matters for the field is the perspective and outcome, not so much the disciplinary input.

Despite acceptance within many medical courses (at least as an optional module), the place and value of the humanities in a medical curriculum is still a matter of debate, particularly in terms of outcomes-based evidence. As Ousager and Johannessen ${ }^{6}$ have noted, the medical humanities literature has been more focussed on 'pleading their case' and justifying ideologically its inclusion in medical curricula, with less focus on seeking or collecting evidence of its impact. The inherent challenge of 'proving' any educational outcome is only part of the reason for this, although a very important one, as highlighted by the claim that education might well be the "hardest science of all'. ${ }^{7}$ The resistance to documenting outcomes may also be partially philosophical, stemming from a strong, almost visceral sense that to seek justification in empirical evidence is to compromise the goals, values and possibly even epistemologies of the humanities. Nevertheless, Ousager and Johannessen 
are no doubt correct to argue that the medical humanities would be well served to be able to proffer evidence of its pedagogical outputs, outcomes or impact, although this argument would seem to apply just as much (theoretically, if not to the same extent politically) to other disciplines in the medical curriculum.

Some progress has recently been made in this endeavour - particularly in supporting the effect on student or practitioner observational skills, empathy, narrative competence, and other professional attributes, such as reflective practice, self-care and tolerance of ambiguity. ${ }^{8-15}$ But that is not the scope of this article. Rather, the intention here is to look more closely at the arguments in the literature which have been made to justify the place of the humanities in the medical curriculum, with an emphasis on recent scholarship which sees the humanities as offering important support to particular 'ways of knowing' claimed to be at the heart of clinical practice..

\section{Justifications for the medical humanities}

While justifications for the medical humanities have been articulated in various ways, they are commonly catgeorised as essentially instrumental or non-instrumental. ${ }^{16}$ The instrumental approach is possibly the easier sell in medical education, with its emphasis on the development of knowledge, skills or habits to produce 'better' doctors, ${ }^{17}$ or as Macnaughton succinctly states:

[H] umanities subjects, particularly literature, can be seen as a source of case histories for medical students; and the humanities can teach students certain skills which may be of benefit to them in the clinical situation. ${ }^{16}$

Other more practical claims stemming from an instrumental perspective include facilitation of observation skills, empathy, communication and other clinically relevant skills. This 
approach can be seen as a precursor to broader claims about the value of the humanities for the development of professionalism in medical education. ${ }^{18}$

On the other hand, the non-instrumental justification for the medical humanities sees 'intrinsic' value in the studies of the humanities in medical education contexts. ${ }^{16}$ This approach emphasises the inherent value of a liberal education in a learned profession such as medicine, ${ }^{19}$ but can also lead to stronger claims of the 'remedial' effect of studying content traditionally associated with the humanities disciplines, particularly as a response to the perception that the increasing biomedical and technological emphasis of medical teaching and practice threaten to undermine the caring role of modern medicine. The humanities are accordingly seen as an antidote to this trend, as a way of improving patient care, (re)instilling patient-centred values in medicine and essentially 'humanising' the medical profession. ${ }^{20}$ Ambitious and rhetorically compelling as it is, such a claim is however easily challenged by the simple observation that not everyone who appreciates or has been exposed to the humanities necessarily acts in a 'humanistic' manner. ${ }^{21}$

An alternative justification has recently been identified and described as 'intellectual', which:

enables and encourages fearless questioning of representations of caregivers and patients in all their varieties, challenges abuses of power and authority, and steadfastly refuses to accept the boundaries that science sets between biology and culture. $^{22}$

A similar description is offered by Cole et al. ${ }^{2}$ Both focus on what is probably better called the 'critical' function of the medical humanities, as proposed by various medical humanities scholars $^{23,24}$. Rather than claiming that such a role is intended to be 'of service' to medical training in the traditional curricular sense, such scholars conceptualise the humanities as providing a form of 'creative tension' with traditional medical curricula by bringing a critical, independent and at times frankly subversive lens to its activities. The terms used to describe this engagement by an 'outsider' discipline are commonly metaphoric but illuminating: 'productive entanglement', ${ }^{23}$ 'redistribution of sensibility', ${ }^{24}$ and radical hermeneutics. ${ }^{25}$ In 
fact, the critical perspective has been an important rationale for the medical humanities since its inception, drawing on inspiration from landmark works such as Illich's Limits of Medicine. Recent re-articulations however seem to acknowledge more explicitly the pedagogical context in which the critical perspective can, and perhaps needs to, function. ${ }^{24}$

This paper contends that a fourth category - an epistemological perspective - is also evident in the medical humanities literature, in which the medical humanities is claimed to represent characteristic ways of understanding and practicing medicine, which are not adequately represented by instrumental, intrinsic or critical categories. Of course, such categorisations are seldom clear-cut and must be interpreted as potentially overlapping. Even the critical function outlined above, which may appear to take an adversarial stance towards traditional medical curricula, ultimately seeks productive and useful outcomes for clinical medicine. Intrinsic justifications, too, imply that the practitioner is improved in such a way that concomitant benefits flow to patient care. Moreover, the notion of instrumentalism in a pedagogical context can be problematic, since most rationales for the medical humanities ultimately claim to have a beneficial effect on the learner and, down the track, clinical practice, and therefore may be seen as instrumental in some way. But let us continue to confine the instrumental to the notion of separately identifiable skills which may be independently facilitated, and whose characteristics may be transferred to clinical contexts. The epistemological justification then represents a claim beyond such specific utility; its essence lies in claims about requisite knowledge and reasoning, an idea hinted at in an early articulation of the medical humanities as concerned with the 'nature, goals and knowledge base of medicine itself' ${ }^{26}$

There is considerable value in identifying such an alternate perspective. Not only does it strengthen potential arguments for the place of the medical humanities, but it also helps focus attempts at identifying and documenting relevant learning outcomes of medical curricula. It can also uncover other evidence from educational outcomes research which may not have been the focus of previous inquiry from the medical humanities and which may in fact be associated, at least in part, with a humanities perspective. Most importantly, an epistemological perspective advances the question of the incorporation of the humanities in medical education from if to the more crucial question of how humanities content, methods or perspectives are best included and utilised in the curriculum. 


\section{Epistemological perspectives}

That medical practice is both an art and science is axiomatic. But the assertion of medicine as an art can be made in a weak sense or a stronger one. In the former case, it is a loose way of signifying the more subjective elements of clinical practice which are commonly tacit and difficult to teach, such as understanding the patient's deeper concerns or identifying unusual or unexpected presentations. These relate to a form of judgement which is highly contextual and possibly intuitive. The stronger sense refers to the way that the specific content or methods of 'art' - commonly understood as the tertiary disciplines associated with the 'arts and humanities' (and often also the social sciences) - to a certain extent characterise professional practice.

The most obvious way in which the medical humanities literature appeals to an epistemological perspective in asserting the importance of the field is through the notion of 'ways of knowing' (or understanding, thinking, etc). The concept has received more explicit consideration in the field of nursing, where the four ways of knowing proposed by Barbara Carper - empirical, ethical, (a)esthetic and personal - have for many come to represent the epistemological basis of nursing. ${ }^{27}$ Medical education in general appears not to have embraced the concept of underlying epistemologies quite so enthusiastically (or at least openly), but a spike in interest over the past $10-15$ years is clearly discernible. The common factor in these studies is the desire to identify and explain what it is about the nature of the humanities disciplines, and their methods of inquiry, which can prove productive when applied to the pedagogical and practical contexts of health care. Most importantly, they argue that epistemologies derived from or exemplified by the humanities are integral, or indeed constitutive, of clinical practice.

An early expression of this perspective may be seen in the proposed attributes of the 'good doctor' by Macnaughton, ${ }^{16}$ where it is suggested that the necessary clinical judgement is made up of 'technical' and 'humane' components, unified by interpretation and insight, 
which, in turn, are underpinned by science on the one hand and arts and humanities on the other. In explaining how these two domains combine to form clinical judgement, Macnaughton emphasises their mutual influence and interconnectedness, and their ultimate filtering through an interpretive lens, governed by the particularities of the patient and clinical context. Macnaughton's summary of clinical judgement can be seen as an attempt to make the 'art element' of medicine more explicit and more than simply an article of faith - even while the foundational nature of scientific understanding is never in doubt.

A very different and much more detailed exposition of this issue is taken up by Karen Montgomery in her book How Doctors Think. ${ }^{28}$ Montgomery's stance is essentially the opposite of Macnaughton's - how is medicine actually scientific? From her perspective, the kind of reasoning which doctors customarily engage in is a 'flexible, interpretive, ineradicably practical rationality', and medicine is therefore 'misdescribed' as a science, if by the term we understand the 'popularised' version of science as fixed, positivist, and valueneutral. Rationality remains its core epistemology, but it is of a very different kind to the logico-deductive reasoning which 'idealised' versions of science portray (which Montgomery is quick to point out are inaccurate and outdated). To therefore label medicine a science is to misrepresent it in practice, and more importantly, epistemologically; and, as Montgomery argues, to misrepresent the epistemology of medicine has serious repercussions - for patients, the profession and physicians. In language designed to both provoke and persuade, Montgomery calls this an epistemological blind-spot, or scotomanot unlike Rumsfeld's 'unknown unknowns' perhaps.

The epistemological concept of a 'way of knowing' is clearly entering the lexicon of medical educators. ${ }^{2,29-31}$ Kumagai draws on Habermas to identify three key types of knowledge and interests in medical education (an 'epistemological typology'): instrumental/technical, communicative/practical and emancipatory/critical. Each has corresponding aims, areas of medical education and accepted ways of validating what passes as legitimate knowledge crucial for any epistemological framework. The particular relevance of the humanities in medical education is constructed here as primarily emancipatory/critical, aimed at understanding at the level of self-knowledge, social understanding and professional relationships, which aligns with practice consistent with personal and professional values. 
This is clearly a parallel concept to Carper's in nursing, although with different categories of knowledge. Its influence and usefulness still needs to play out, although a similar application of Habermas has recently been published. ${ }^{32}$ This is a relatively constrained perspective of the epistemology of the humanities in relation to medical education - it is strongly linked to the identification, formation and application of relevant values, but any potential relevance for the instrumental/technical and communicative/practical aspects of medicine is left implicit. However, in emphasising the transformative role of medical education, which emanates from an emancipatory/critical focus, along with his characterisation of medicine as the 'application of (bio)science in the service of human needs and interests in order to alleviate suffering and optimise health' (my italics), Kumagai makes the epistemological centrality of the humanities for medical education very clear.

Boudreau and Fuks ${ }^{30}$ apply the 'way of knowing' framework in a similar way - though with different nomenclature - to argue for a developmental role associated with the formation of enlightened, empathetic and holistic physicians, alongside a more instrumental role for 'honing clinical skills'. The notion that the humanities can help develop particular clinical skills is based on the belief that certain disciplines target specific mental 'faculties', while the developmental argument relies on broader conceptions and metaphors of shaping, nourishment and transformation. Continuing their use of metaphors, the authors consider common claims regarding the contribution of the medical humanities to clinical practice, namely: holistic practice (by balancing the biomedical focus of medicine with the humanistic); self-care; increased patient-centredness; and pedagogical 'radicalisation', the latter term evoking the critical justifications noted earlier. However, Boudreau and Fuks subsequently critique these claims, seeing them as tacitly accepting the pre-eminence of the biomedical-disciplines, and therefore limiting the humanities as additive, artefactual and ultimately disempowering. ${ }^{33}$ Instead, they argue, the medical curriculum must first be fundamentally 'realigned' and 'reframed', in accordance with the relevant goals, concepts and frames of a medical education. 'The humanities', they assert, 'are inseparable from medical practice as cognate disciplines', and can provide the 'essential philosophic, developmental and pedagogical concepts necessary to the task'. This is where the underlying epistemological focus of their argument is at its strongest. 
A similar viewpoint, but very different articulation, of the epistemological justification for the medical humanities is expressed in the paper by Kuper and D'Eon. ${ }^{34}$ Using the methodology of the 'thought experiment', the authors approach the issue of the appropriate basis of medical knowledge inductively and, seemingly, dispassionately. Taking their starting point from representative physician competencies (as defined by prevailing social, cultural, economic, political and pedagogical forces), the authors explore how these competencies might be elucidated and facilitated through curriculum activities, and then consider the content and disciplines that would be pertinent or necessary for this purpose. The methodology of the thought experiment is necessary to side-step the prevailing political reality of the apparently unassailable place of bioscience in the post-Flexnerian medical curriculum, in order to focus on the learning which needs to occur for bright undergraduates to become competent doctors. It also allows the debate to focus on where it matters most in the very curricular activities students are made to endure in the name of learning outcomes. The fact that the authors do not even mention the term 'medical humanities' (there are several general references to the humanities and social sciences) is in fact an asset in their discussion. They have not set out to prove explicitly the value of the medical humanities; rather, they have sought to identify the key and necessary ways of thinking valued in clinical practice - according to prevailing competency frameworks - and then turned to the disciplines which might support and inculcate this. In their own words, their 'results' present

a significant challenge to medical educators, requiring a transformation of the contemporary medical school curriculum in order to authentically address the current inconsistency between its contents and the goals and objectives of the competency frameworks... Medical education is training for competent medical practice, and the only justification for any kind of foundational knowledge is that it will support that practice. ${ }^{34}$

In other words, the key considerations, for both the medical humanities and medical curricula in general, should be foundational and epistemological, not disciplinary or ideological. 
In each of the above studies, medical practice is explicated epistemologically as both 'scientific' - defined by reasoning which is logico-deductive, universalising, generalisable, predictable, and empirical - and 'humanistic', that is, experiential, particularising, contextual, intuitive, and constructed. The humanities are accordingly offered for judgment epistemologically, or on a 'level playing field', as it were. Removed of the 'special pleading' that earlier claims may have been guilty of, epistemological justifications challenge educators to take their own learning objectives, graduate attributes and competency frameworks seriously and at face value. Where synergies exist between those outcomes and relevant disciplines within the humanities, from a pedagogical perspective at least, these must be genuinely and open-mindedly considered for inclusion in the curriculum.

Such distinctions between scientific and humanistic ways of thinking are reminiscent of the quantitative vs qualitative debates in educational research, played out in clinical medicine journals in the contrasting value apportioned to large-scale controlled studies and the serendipitous insights offered by case studies. In the same way that both sources of evidence may be argued to be of value to clinical practice, an epistemological perspective allows the argument that medical education also relies on the content, methods and perspectives of both the natural sciences and the humanities. Yet a crucial question remains: what special epistemologies can the humanities claim which the biosciences or clinical skill subjects do not already provide? Is it not open to the scientific and clinical disciplines to also promote reasoning which aligns with the humanistic qualities outlined above? In other words, do the humanities 'own' humanistic epistemologies?

Evidence exists which suggests this may well be the case. Roex and Degryse ${ }^{35}$ cite recent research which demonstrates the domain-specificity of epistemological beliefs, and educational research supports the notion of 'signature pedagogies', to some extent reflecting different epistemologies, associated with the various academic disciplines. ${ }^{36}$ Further evidence comes from the work of Jerome Bruner, which identifies two irreducible 'modes of thinking', the logico-scientific and the narrative mode:

One verifies by appeal to formal verification procedures and empirical proof. The other establishes not truth but truth-likeness or verisimilitude... the one seeks 
explications that are context free and universal, and the other seeks explications that are context sensitive and particular... One mode is centered around the narrow epistemological question of how to know the truth; the other around the broader and more inclusive question of the meaning of experience. ${ }^{37}$

According to this representation, the two modes reflect fundamentally different epistemologies, and it therefore would follow that these would be best represented by different curricular input. A key element in Bruner's modes of thinking is the distinction between the general and the particular, a distinction central to the academic literature discussed above. Where science privileges that which is common and to some extent predictable between people as patients - and which is the necessary basis for treatments the humanities tend to pay greater attention to the particularities; the individual and contextual factors which make a particular situation or experience qualitatively different from another. Of course these emphases can be reversed - often the exception (the particular) turns out to prove the rule in science, while a fundamentally humanistic epistemology such as empathy relies on a certain generalisability of human thought and experience. But as every discipline is characterised by certain paradigms of thought and method, so to can we assign generalisability and particularity as the special domains respectively of science and humanities.

\section{Implications for medical education and clinical practice}

If the claim that the humanities represent a relevant epistemological foundation for medical training is to prove convincing, then the resultant knowledge or reasoning must find parallels in clinical practice itself. Beyond maxims about the art and science of medicine, the idea that medical humanities scholars keep returning to in order to convey this is the Aristotelian notion of phronesis. This concept has been rendered in various ways - 'practical judgement', 'practical reasoning' or 'clinical rationality' - but is intended to represent more than simply a bringing together of the art and science elements of a professional activity; it is, again, constitutive of professional practice, a unique and particular form of reasoning pertinent to a professional's way of practicing in the relevant context, and indeed the very 
process of professional identity formation. ${ }^{30}$ In their own way, each of the authors discussed above under the banner of epistemological rationales for the medical humanities attempts to explain how the humanities are integral to the phronesis which defines the work of doctors.

Several applications of this simultaneously intellectual and practical activity, and its relationship with humanities-based ways of thinking, are detailed in the articles discussed. But perhaps more concrete examples are also warranted here. The scholarship of clinical reasoning points to the potential epistemological role of the humanities. While a case may be made for the humanities on several fronts, particularly suggestive is the research by Audétat et $\mathrm{al}^{,},{ }^{38}$ who identify five 'prototypical difficulties' faced by students when learning clinical reasoning, several of which would appear to be particularly remediable by the kind of thinking commonly associated with the humanities. For example, in regards to the difficulty of 'fixat[ing] on a single feature of the case' (a form of 'premature closure'), this could be potentially remedied by practice in thinking in terms of plausibility instead of linearity, an emphasis which is arguably a strength of the humanities. When a student 'fails to integrate the patient's perspective and contextual factors' (a form of 'difficulty in prioritising'), they could benefit from the inherent focus of the humanities on the experiential and the particular, rather than allowing their thinking to be (overly) dominated by the scientific epistemology of seeking and valuing the universal elements of disease. In each case, a humanities perspective would provide practice in a particularly way of think, which would then be re-integrated into and transferred to clinical contexts. The intention would decidedly be not to undermine the necessary scientific basis of clinical practice, but to complement it in a way which reinforces key aspects of that practice.

The concept of empathy offers another example of how epistemology affects educational practice. Conceptualising empathy as a clinical skill is likely to lead to training in communication and professionalism skills. By contrast, an emphasis on the epistemological value of empathy (in the context of a humanities programme in medicine), or a particular 'way of knowing', would focus on the crucial understanding of patient circumstances and perspectives that could inform appropriate clinical practice. Rather than (only) providing practice in breaking bad news or effectively expressing empathy, an epistemological 
approach would provide opportunities for imagining, discussing, and explaining interpretations of patient circumstances, with explicit links to clinical practice. It follows that assessment would also focus on probing the quality of that understanding, drawing on methods and frameworks which guide assessment of the qualitative and interpretive elements of thinking in the humanities disciplines. Such a shift of emphasis would of course need to be reflected in the relevant objectives and course outcomes. The translation of such perspectives and understanding into observable behaviours and clinical practice may be neither automatic nor easy, and therefore would remain a concern of clinical educators, but this is true of all clinical teaching and outcomes. Acknowledging the epistemological intent behind the education of empathy would clarify its purpose and focus, and allow the transition to a clearer and stronger focus on the relevant behavioural and clinical outcomes.

Narrative competence and professional identity formation are two others areas where an epistemological view changes the way these areas are conceptualised and represented in a curriculum. As explicated in the works of Rita Charon, for instance, narrative competence not only underpins the basis of the signature clinical practice of taking a patient history, but it also represents the very medium by which medicine is practiced. ${ }^{39}$ The view that 'what the scalpel is to the surgeon, words are to the clinician' ${ }^{40}$ reflects the epistemological claim that narrative - and by extension, the disciplines which make it their focus of study - is a constitutive element of medical practice. Furthermore, specific activities involved in the study of literature, such as close reading, critical reflection and 'countercultural perspectives' have recently been linked to the process of professional identity formation.

The connections exemplified above are not necessarily self-evident. As Campo ${ }^{43}$ and also Knight $^{44}$ have shown, the idea and claims of the 'medical humanities' are often met with bemusement if not resistance. Yet, as Knight's study shows, many clinicians would readily endorse the importance of and relevance to everyday practice of issues commonly associated with medical humanities reasoning. It is therefore up to educators to make such links between a humanities curriculum and clinical practice more explicit and compelling. The notion of epistemological perspectives seems a promising way of doing this. 
But are the humanities for everyone? The foregoing discussion raises the issue of whether the humanities might only be valuable for those 'so inclined'. The fact that the humanities are offered only as optional modules in many medical programmes might suggest this to be the case. This brings us back to the focus of this paper of how one justifies the humanities in medicine, or rather what a school is prepared to accept as justification. An instrumental view might lead to the decision that the relevant skills which the humanities might facilitate could just as adequately (and less inconveniently) be gained by other means (and possibly after graduation). A non-instrumental view would be vulnerable to the counter-claim that while character is nice, technical skill is better, and curriculum decisions made accordingly. The epistemological perspective runs deeper and provides an argument for the humanities being essential to a medical programme: if the content, methods or perspectives of the humanities align with the kind of thinking necessary to good clinical practice, then its inclusion cannot be regarded as optional.

\section{Conclusion}

The point of the preceding discussion is not categorical neatness. Clarifying the basis for claims about the medical humanities facilitates the kind of studies of outcomes which critics of the medical humanities have called for. Identification and clarification of this epistemological perspective of the medical humanities, along with a greater emphasis on the outputs of a medical education, as Kuper and D'Eon have modelled, should facilitate a more balanced and less defensive discussion of its place in the medical curriculum. If the medical humanities does usefully represent and underpin key elements of conceptualising medical practice, then its value is constitutive rather than instrumental, intrinsic or critical (in the perspective sense). The debate accordingly shifts to not if but how, how well and how much the humanities should be in a medical curriculum - all thoroughly epistemological considerations.

This 'epistemological imperative' offers a significantly new way of conceptualising and communicating the potential role of the humanities in medical education. Thinking is habit forming and it is both misleading and counterproductive to allow practice in ways of 
knowing that may not subsequently serve clinical learners well. If clinical practice is rational but interpretive, partly predictable yet fundamentally uncertain, logical but also intuitive, then educational training must embrace and exemplify this. From an epistemological perspective, the medical humanities deserve to sit equally alongside the medical sciences, not because they are more 'humane', but because they help constitute what it means to think like a doctor.

\section{REFERENCES}

1. Steyn M. Rummy speaks the truth, not gobbledygook. The Telegraph. December 92003.

2. Crawford $P$, Brown B, Tischler V, Baker $C$. Health humanities: the future of medical humanities? Mental Health Review Journal. 2010;15(3):4-10.

3. Cole TR, Carlin NS, Carson RA. Ways of knowing. In: Medical Humanities: An introduction. Cambridge: Cambridge University Press; 2015; 213-24.

4. Bleakley A. When I say ... the medical humanities in medical education. Medical Education. 2015;49 (10): 959-60.

5. Evans M. Reflections on the humanities in medical education. Medical Education. 2002;36(6):508-13.

6. Ousager J, Johannessen $\mathrm{H}$. Humanities in undergraduate medical education: a literature review. Academic Medicine. 2010;85 (6):988-98

7. Berliner DC. Comment: Educational research: the hardest science of all. Educational Researcher. 2002;31 (8):18-20.

8. Dolev, J., Friedlander, L., \& Braverman, I. Use of fine art to enhance visual diagnostic skills. Journal of the American Medical Association. 2001:286: 1020-1021

9. Frank and Martin. Humanities and geriatric education. Can Ger J, 2015. 18(1): 37-41.

10. Chen I, Forbes C. Reflective writing and its impact on empathy in medical education: systematic review. J Educ Eval Health Prof. 2014; 11:20.

11. Kidd DC, Castano E. Reading literary fiction improves theory of mind. Science. 2013;342 (6156):377-80.

12. Peterkin A, Roberts M, Kavanagh L, Havey T. Narrative means to professional ends: New strategies for teaching CanMEDS roles in Canadian medical schools. Canadian Family Physician. 2012;58 (10):e563-e9.

This article is protected by copyright. All rights reserved 
13. Bleakley A, Brennan N. Does undergraduate curriculum design make a difference to readiness to practice as a junior doctor? Medical Teacher. 2011;33(6):459-67.

14. Shapiro J, Morrison E, Boker J. Teaching empathy to first year medical students: evaluation of an elective literature and medicine course. Education for health. 2004 Mar;17(1):73-84.

15. Chen JY, Salter DJ, Chan LC. Pen, brush and camera: outcomes-based medical humanities. Medical Education. 2010;44 (11):1139.

16. Macnaughton J. The humanities in medical education: context, outcomes and structures. Medical Humanities. 2000;26 (1):23-30.

17. Gillon R. Welcome to medical humanities--and why. Journal of Medical Ethics. 2000;26 (3):155-6.

18. Shapiro J, Coulehan J, Wear D, Montello M. Medical humanities and their discontents: definitions, critiques, and implications. Academic Medicine. 2009;84 (2):192-8.

19. Pellegrino ED. Editorial: Medical practice and the humanities. New England Journal of Medicine. 1974;290 (19):1083-5.

20. Gordon JJ. Humanising doctors: what can the medical humanities offer? Medical Journal of Australia. 2008;189 (8):420-1.

21. Jones AH. Reflections, projections, and the future of literature-and-medicine. In: Wear D, Kohn M, Stocker S, editors. Literature and medicine: a claim for a discipline. McLean, Va: Society for Health and Human Values; 1987. p. 29-40.

22. Jones T, Wear D, Friedman LD. Health humanities reader. New Brunswick, New Jersey and London: Rutgers University Press; 2014.

23. Viney W, Callard F, Woods A. Critical medical humanities: embracing entanglement, taking risks. Medical Humanities. 2015;41 (1):2-7.

24. Bleakley A. Medical humanities and medical education: how the medical humanities can shape better doctors. London and New York: Routledge; 2015.

25. Wear D, Aultman JM. Creating difficulties everywhere. Perspectives in biology and medicine. 2007;50 (3):348-62.

26. Greaves D, Evans M. Medical humanities. Medical Humanities. 2000;26(1):1-2.

27. Zander PE. Ways of knowing in nursing: the historical evolution of a concept. Journal of Theory Construction and Testing. 2007;11(1):7-11. 
28. Montgomery K. How doctors think: clinical judgment and the practice of medicine. Oxford: Oxford University Press; 2006.

29. Kumagai AK. From competencies to human interests: ways of knowing and understanding in medical education. Academic Medicine. 2014;89 (7):978-83.

30. Boudreau JD, Fuks A. The humanities in medical education: ways of knowing, doing and being. Journal of Medical Humanities. 2014;36 (4):321-36.

31. Moreno-Leguizamon CJ, Patterson JJ, Rivadeneira AG. Incorporation of social sciences and humanities in the training of health professionals and practitioners in other ways of knowing. Research and Humanities in Medical Education [Internet]. 2015 SEP 25 [cited 2016 May 27];2; http://www.rhime.in/ojs/?p=1132

32. Walker P, Lovat T. Applying Habermasian "ways" of knowing to medical education. J Contemp Med Edu. 2015;3 (3):123-6.

33. Chiavaroli N, Ellwood C. The medical humanities and the perils of curricular integration. Journal of Medical Humanities. 2012;33 (4):245-54

34. Kuper A, D'Eon M. Rethinking the basis of medical knowledge. Medical Education. 2011;45 (1):36-43.

35. Roex A, Degryse J. Introducing the concept of epistemological beliefs into medical education: the hot-air-balloon metaphor. Academic Medicine. 2007;82 (6):616-20.

36. Shulman LS. Signature pedagogies in the professions. Daedalus. 2005;134(3):52-9.

37. Bruner J. Narrative and paradigmatic modes of thought. In: Eisner E, editor. Learning and Teaching the Ways of Knowing. National Society for the Study of Education; 1985.

38. Audétat M-C, Dory V, Nendaz M, Vanpee D, Pestiaux D, Junod Perron N, et al. What is so difficult about managing clinical reasoning difficulties? Medical Education. 2012;46 (2):216-27.

39. Charon R. Narrative medicine: Honoring the stories of illness. Oxford: Oxford University Press; 2006.

40. Tumulty P. What is a clinician and what does he do? New England Journal of Medicine. 1970; 283: 20-24.

41. Shapiro J, Nixon LL, Wear SE, Doukas DJ. Medical professionalism: what the study of literature can contribute to the conversation. Philosophy, Ethics, and Humanities in Medicine. 2015;10 (1):1-8.

This article is protected by copyright. All rights reserved 
42. Monrouxe LV, Rees CE, Hu W. Differences in medical students' explicit discourses of professionalism: acting, representing, becoming. Medical Education. 2011;45(6):585602.

43. Campo R. A piece of my mind. "The medical humanities," for lack of a better term. JAMA. 2005;294 (9):1009-11.

44. Knight LV. A silly expression: Consultants' implicit and explicit understanding of Medical Humanities. A qualitative analysis. Medical Humanities. 2006;32 (2):119-24.

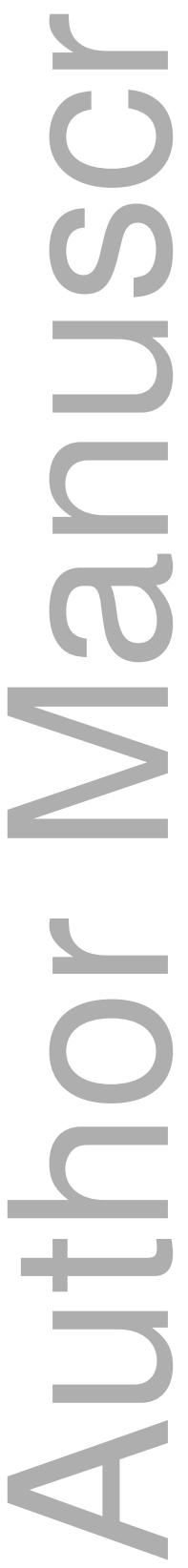




\section{University Library}

\section{- M M N E R VA A gateway to Melbourne's research publications}

Minerva Access is the Institutional Repository of The University of Melbourne

Author/s:

Chiavaroli, N

Title:

Knowing how we know: an epistemological rationale for the medical humanities

Date:

2017-01-01

Citation:

Chiavaroli, N. (2017). Knowing how we know: an epistemological rationale for the medical humanities. MEDICAL EDUCATION, 51 (1), pp.13-21. https://doi.org/10.1111/medu.13147.

Persistent Link:

http://hdl.handle.net/11343/292230 